\title{
AN APPARATUS FOR QUANTITATIVE ESTIMATIONS INVOLVING DISTILLATION.
}

\author{
By GILBERT T. MORGAN AND TAYLOR COOK, B.Sc.
}

THe opэration of distillation is so frequently employed in analytical chemistry that it is scarcely necessary to emphasise the importance of carrying out the process in apparatus suitably arranged for separating quantitatively the volatile and nonvolatile constituents of the material under examination without risk of contamination from extraneous substances derived from corks and indiarubber stoppers or connections. It is with this object in view that, in recent years, many pieces of apparatus have been devised in which cork or indiarubber fittings have been replaced by groundin stoppers and joints. Apparatus arranged in this way is more costly and less easily repaired than a series of distilling flasks and receivers connected with cork or indiarubber stoppers, but these disadvantages are more than compensated by the increased accuracy and certainty of the results obtained; moreover, certain operations involving the use of corrosive liquids or vapours cannot be performed satisfactorily unless the apparatus is constructed entirely of glass, or some other equally resistant material.

One of us (Trans. Chem. Soc., 1904, 85, 1002; Analyst, 1904, 29, 268) has described a modification of Piloty and Stock's method for the separation of arsenic and antimony (Ber., 1897, 30,1649), in which a distilling apparatus with ground-in glass connections was employed. The process, as carried out in this apparatus, has since been applied with uniform success to the analysis of tetrahedrite ("fahl ore") and other arseniferous minerals. The apparatus has also been utilised in the quantitative hydrolysis of organic amides, such as acetanilide and oxanilide.

As the addition of a few modifications to the original apparatus seemed likely to render it serviceable for a much more extensive range of estimations, we have devised the apparatus described in the present paper.

The original distilling apparatus consisted essentially of a Wurtz flask (about 300 c.c. capacity), the outlet tube of which carried a Kjeldahl safety bulb, and was elongated and bent first upwards and then downwards, so that it finally dipped into a large conical receiving flask. The ground-in stopper of the distilling flask formed part of an inlet tube passing almost to the bottom of the vessel.

In the modified apparatus the general principle of the older form is maintained, but the ground-in stopper, $b$, of the distilling flask, $a$ (capacity 1,300 c.c.), is modified so as to admit of the introduction during distillation of a liquid as well as a gaseous reagent, the gas or vapour being introduced through the side tube, $c$, whilst the liquid is added through the tap-funnel, $d$, which forms a vertical prolongation of the hollow stopper. The outlet tube, $e$, carries a safety Kjeldahl bulb, $f$ (about $1 \frac{1}{2}$ inches 
in diameter), and is afterwards bent round and made to terminate in a ground-glass end fitting tightly into the top of a condenser, $g$, which is conveniently of the form devised by Cribb. The outlet tube of this condenser is elongated sufficiently to allow of its dipping under the surface of any absorbent liquid contained in the receiver (not shown). This receiver generally takes the form of a conical flask with Peligot

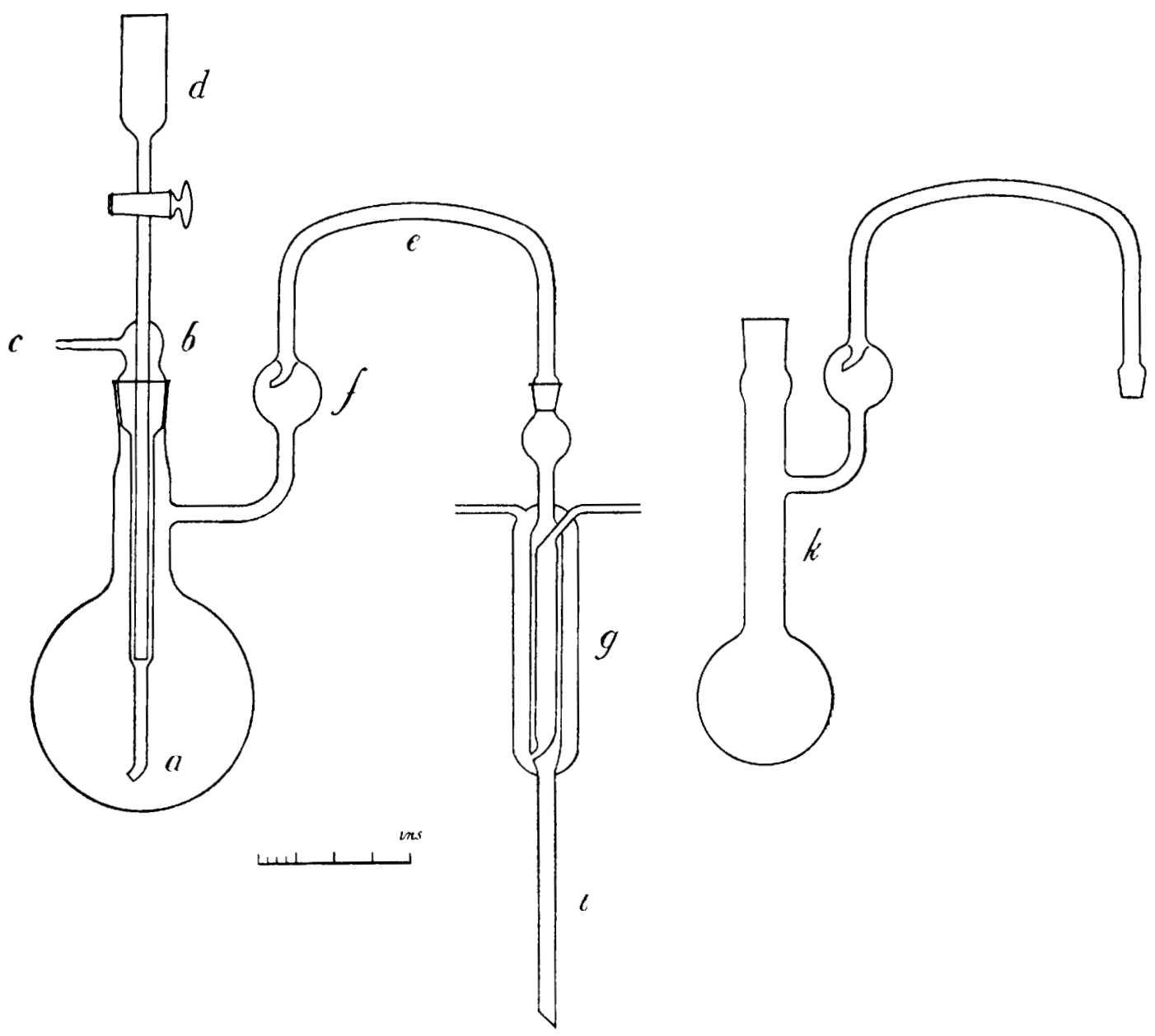

safety tubes, but the size and shape of the vessel are varied according to the requirements of the estimation.

The apparatus is also provided with a duplicate distilling flask, $k$, of smaller capacity ( 300 c.c.), the neck of which is made somewhat longer than that of the large distilling flask, in order that the inlet tube may almost reach the bottom of the vessel in each case. The neck of the smaller flask and the ground-glass termination of its side tube fit the same stopper and condenser respectively as those employed with the large flask. 
This duplication of the distilling flask enables one to carry out operations with varying volumes of liquid, and does not greatly add to the cost of the apparatus.

The following estimations are cited as examples of analytical processes which can be conveniently carried out in this apparatus, but the list is by no means exhaustive :

1. Estimation of Ammonia in Ammonium Salts.-The substance is distilled with either aqueous caustic soda or milk of lime, the smaller flask being generally employed in this analysis. Volatile organic amines could obviously be estimated in a similar manner. The base is in each case expelled with steam.

2. Estimation of Nitrates and Nitrites by Reduction to Ammonia.-..These substances were reduced with Devarda's alloy (aluminium.copper couple) and dilute caustic soda. The distillation was effected in a current of steam.

3. Estimation of Nitrogen by Kjeldahl's Method.-After destroying the organic matter in the customary manner, the contents of the decomposition flask, considerably diluted with water, were transferred to the larger distilling flask, rendered alkaline with caustic soda, and distilled in steam.

4. Estimations involving the Distillation of Chlorine.-Substances evolving chlorine on treatment with hydrochloric acid can be analysed in this apparatus, the distillation being carried out in a current of air or carbon dioxide. The smaller flask is generally employed in these estimations, and is conveniently heated to boiling in a glycerine or fusible metal bath. This mode of conducting the operation in a current of some inert gas is preferable to distillation in closed vessels, inasmuch as by the former arrangement the internal pressure of the distilling flask need never differ greatly from the atmospheric pressure, thus avoiding any risk of regurgitation from the receiver into the distilling flask. In these experiments the condenser has the useful effect of cooling thoroughly the hydrochloric acid solution which distils over, so that the risk of decomposing any hydrogen iodide by local heating is reduced to a minimum.

5. Separation of the Halogens. - This apparatus is suitable for the separation of chlorine, bromine, and iodine, when present in the form of soluble halide salts, by Jannasch and Aschoff's method (Zeit. anorg. Chem., 1892, 1, 144 and 245 ; also Classen's Ausgewählte Methoden der Analytischen Chemie, vol. ii., p. 402). A mixture containing approximately 0.5 gram each of potassium chloride, bromide, and iodide was introduced into the larger flask, and treated with 1 gram of sodium nitrite and 5 c.c. of $2 \mathrm{~N}$-sulphuric acid dissolved in 750 c.c. of water, the mixture being then distilled in steam until the iodine was entirely expelled, and collected in an aqueous solution of 2.5 grams of sodium hydroxide and 50 c.c. of pure hydrogen peroxide. The liquid in the receiver was boiled with more hydrogen peroxide, to decompose any nitrite, and the iodide then estimated as silver iodide. The solution in the distilling flask was rendered slightly alkaline with sodium hydroxide, concentrated to 500 c.c., treated with 1 to 1.5 grams of potassium permanganate and 60 c.c. of acetic acid ( 1 acid, 2 water), and again distilled in steam until all the bromine was expelled and converted in the receiver into sodium bromide by the action of sodium hydroxide and hydrogen peroxide. The final residue in the distilling flask was treated with alcohol 
and sodium hydroxide, to remove excess of manganese, and the chloride estimated as silver chloride.

6. Estimation of Boric Acid.-In this estimation the method of Rosenbladt and Gooch was followed (Zeit. anal. Chem., 1887, 26, 18 and 364), the distillation being effected in the smaller flask at $140^{\circ} \mathrm{C}$. The volatilised boric acid was collected in milk of lime containing a known weight of calcium oxide, and weighed as ignited calcium borate.

7. Separation of Arsenic and Antimony (Thorpe, Quantitative Analysis, ed. 1891, p. 277; and Trans. Chem. Soc., 1904, 85, 1002). - In the analysis of tetrahedrite and other arseniferous minerals the finely powdered substance is heated in a current of chlorine until the chlorides of arsenic and antimony are expelled and collected in a solution of tartaric acid in concentrated hydrochloric acid, from which the sulphides of these elements are subsequently precipitated by hydrogen sulphide. The mixed sulphides suspended in concentrated hydrochloric acid are distilled in the apparatus in a current of hydrogen chloride, the arsenic being volatilised as chloride, and reprecipitated as sulphide in an ice-cold saturated solution of hydrogen sulphide contained in the receiver. A sample of tetrahedrite gave the following percentuge results: $\mathrm{As}=2 \cdot 23,2 \cdot 16: \mathrm{Sb}=11 \cdot 68,11 \cdot 74$.

It has already been pointed out by one of us (ANALYst, 1904, 29, 268) that the distillation in hydrochloric acid as carried out in this apparatus may be employed to separate arsenic in its two states of combination, providing that the acid employed does not at any stage come into contact with organic materials, for, as Hehner has shown (ibid., 1902, 27, 268), boiling hydrochloric acid free from organic or other reducing agents does not effect any considerable reduction and consequent volatilisation of arsenic present in the quinquevalent condition.

8. Proximate Organic Analyses - (a) Estimation of Acetic Acid in Acetates and Acetyl Derivatives. -The smaller distilling flask was employed, and the acetate or acetyl derivative distilled in steam with excess of phosphoric acid, the flask being heated in a glycerine bath. The acetic acid was collected in standard caustic soda. Acetanilide and "aspirin" (acetyl-salicylic acid) were chosen as types of acetyl compounds which are amenable to this treatment. The process is applicable to the estimation of other volatile acids.

(b) Estimation of Methoxyl by Zeisel's Method.-We find that the smaller flask, with its long neck and bent side tube, giving a total length of 12 inches from the bulb of the flask, plays the same part as the long-necked Wurtz flask employed by W. H. Perkin, sen., in a simple modification of Zeisel's process (Trans. Chem. Soc., $1903,83,1368$ ), whereby a fractionation of hydriodic acid and methyl iodide is effected, the latter alone distilling forward.

The outlet tube of the condenser $g$ is placed directly over the alcoholic silver nitrate, so that the vapour of methyl iodide never comes into contact with absorbent corks or india-rubber fittings until it has been at least once in contact with the silver solution. For comparatively simple compounds the hydriodic acid (specific gravity $1 \cdot 68$ to $1 \cdot 70$ ) was used alone, but with more complex substances it was mixed with acetic anhydride. 
A proximate analysis of phenacetin (acetyl-p-phenetidine) showed that the apparatus may also be employed in the estimation of ethoxyl.

Summary of Analytical Results.

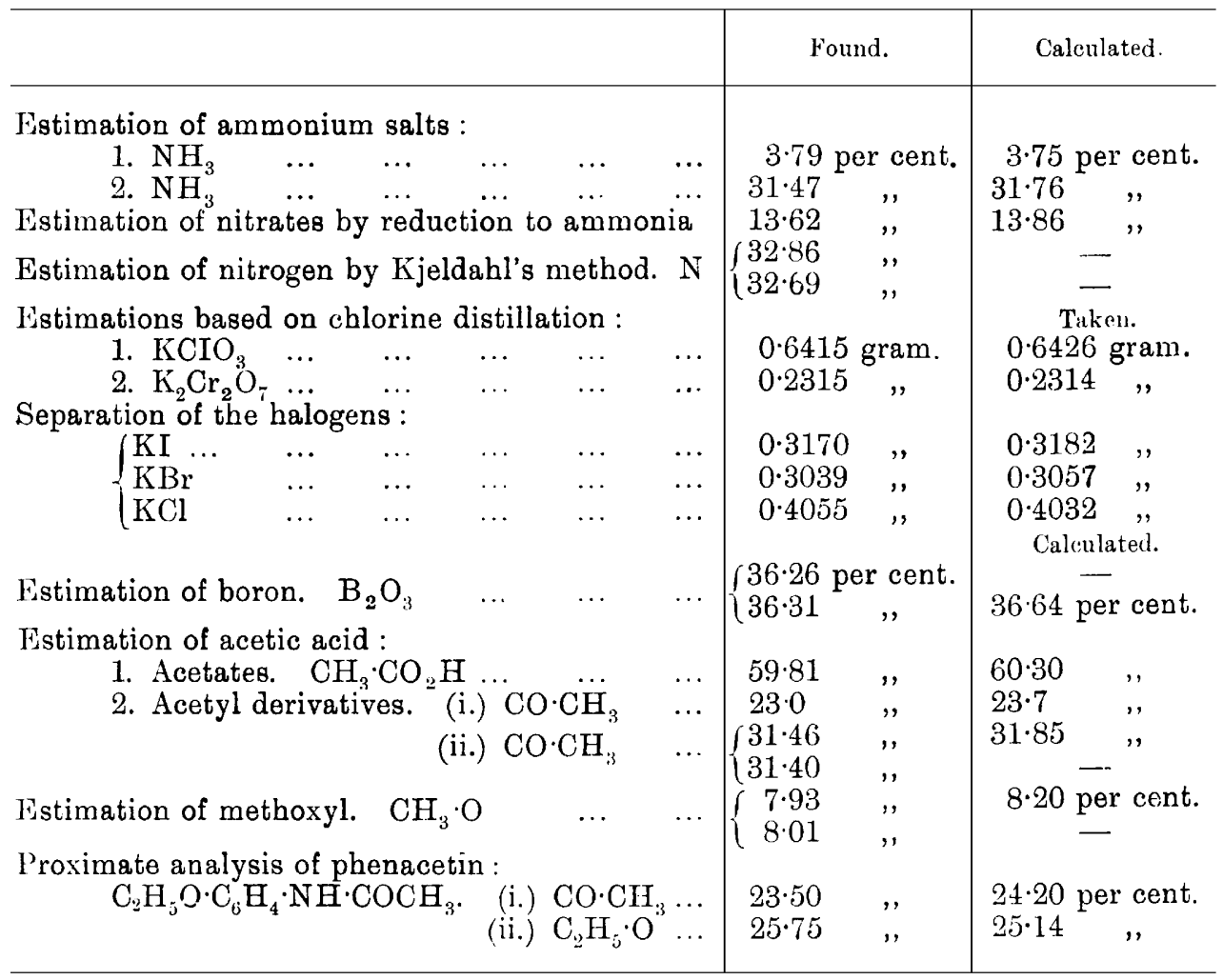

Royal College of Science, Loxidos,

Sotth Kexsington, S. IN 